\title{
Benveniste: enunciação e referência
}

\author{
Sílvia Helena Barbi Cardoso \\ Universidade Federal de Uberlândia
}

\section{Abstract}

The aim of this paper is to show how concerned Benveniste was with the theme of 'reference' or the relationship between language and reality. The reintroduction of this theme into Linguistics breaks new ground by showing how the study of language can be combined with an interest in broader problems of social analysis. Benveniste provides a concise and critical review of the problem of 'meaning' in Linguistics. In spite of being accused of a lack of historical postulates, Benveniste's contributions are of paramount importance for discourse analysis, especially in the French tradition. 
O próprio da linguagem é, antes de tudo, significar.

Benveniste

\section{INTRODUÇÃO}

$\mathrm{P}$ ode-se dizer que o discurso da Lingüística do século XX se caracteriza pela maneira pela qual institui seus objetos. Saussure já tinha consciência de que a Lingüística não é a ciência de um objeto dado, mas a ciência de um objeto posto ou instituído por ela mesma. Já nas primeiras páginas do Curso de lingüística geral (na verdade o curso de introdução geral que Saussure deu em Genebra de 1907 a 1911 e que Bally e Sechehaye publicaram na forma do livro sobre o qual se edificou toda a lingüística moderna), Saussure revela a sua preocupação de determinar o valor da Lingüística e de distingui-la de todas as outras ciências. Declara a necessidade que a Lingüística tem de, "diferentemente de outras ciências", preocupar-se em determinar a natureza de seu objeto de saber e de delimitar-se e definir-se a si própria. Isto equivale a dizer que a Lingüística está orientada para o seu próprio discurso, na constituição do seu objeto, nos questionamentos acerca de seus fundamentos, processos, modelos, pressupostos, etc.

Se para Saussure (1916) o "objeto instituído" é privilégio da Lingüística, aliás uma Lingüística teórica muito exigente, que procura formular-se como ciência, para Foucault (1969), não se trata de prerrogativa alguma. Nenhuma ciência ou disciplina trabalha com objetos dados previamente, esperando apenas ser descobertos, nomeados, classificados, relacionados. Os objetos das ciências ou disciplinas não pre-existem à sua prática, podendo ser referidos como alguma coisa que existe de per si, mas todo objeto é constituído pelo discurso e transformado no discurso de acordo com as regras de uma determinada formação discursiva, ou seja, é determinado por essa prática. Assim, para Foucault (1969 e 1971), 
uma disciplina não é um conjunto de discursos e esses discursos não são conjuntos de signos que remetem a conteúdos ou representações, mas sim práticas discursivas que formam sistematicamente os objetos de que falam.

Com relação ao objeto da lingüística moderna, pode-se dizer que não se manteve único ou estável nesses quase cem anos de história, nem o seu domínio de formação manteve qualquer estabilidade. A língua enquanto sistema é o objeto do discurso da Lingüística da primeira metade do século XX, mas a partir da segunda metade, são admitidos outros objetos além da língua: o discurso, o texto, a enunciação.

É sobretudo nos trabalhos do lingüista francês Émile Benveniste que o domínio dos objetos no discurso da Lingüística evidencia um deslocamento bastante considerável, a ponto de mudar os rumos da Lingüística da segunda metade do século, sobretudo no solo europeu.

São muitos os trabalhos de Benveniste que podem ser considerados notáveis com respeito a esse deslocamento. Aqui, darse-á relevo aos textos mais recentes, sobretudo um texto de 1968, Semiologia da língua, outro de 1970, O aparelbo formal da enunciação, e um terceiro de 1966, A forma e o sentido na linguagem. Serão considerados, também, alguns textos mais antigos, dentre outros, Natureza do signo lingüístico, de 1939, A natureza dos pronomes, de 1956 . Esses serão referidos, ou para se mostrar a evolução sofrida pela reflexão teórica do autor, ou para se mostrar algum traço que se manteve constante em toda sua obra.

Em Semiologia da lingua, Benveniste propõe duas modalidades ou dois domínios de sentido, o semiótico e o semântico, na verdade uma proposta de ultrapassar a noção saussuriana de signo como princípio único (noção que havia bloqueado a semiologia da língua com o fechamento dos signos no interior do sistema), e com a qual pretende dar conta simultaneamente da estrutura e do funcionamento da língua. Essa ultrapassagem, diga-se de passagem, a grande tese de Benveniste, com a novidade do modo "semântico" 
de significar da língua, que não estava contido no Cours, exige novos objetos, novos temas. Entre os objetos novos, o discurso e a enunciação; entre os temas, sem dúvida, o tema da referência, objeto deste artigo. As questões do discurso e da enunciação e o tema da "subjetividade da linguagem" sustentam décadas do trabalho de Benveniste, mas são tratadas com o máximo de requinte teórico no texto de 1970, O aparelho formal da enunciação.

Benveniste tinha consciência das limitações do alcance do seu trabalho. Sabia da necessidade de um novo aparato teórico para dar conta da "Semiologia de Segunda Geração" que ele estava a propor, e da qual restava quase tudo por fazer. A Lingüística de Saussure (que Benveniste em momento nenhum rejeitou) poderia dar perfeitamente conta do modo de significação semiótico, mas não do semântico. Se o primeiro, que é próprio do signo lingüístico, considerado enquanto unidade ou elemento do sistema, e que trata da identificação das unidades sígneas, da descrição de suas marcas distintivas, de critérios cada vez mais sutis de sua distintividade, já se encontrava suficientemente desenvolvido e demonstrado em nível científico, o segundo, o semântico, engendrado pelo discurso, ou seja, pela lingua em funcionamento, enquanto produtora de mensagem, estava ainda a exigir desenvolvimento e demonstração, para elevar-se do nível pessoal do seu próprio trabalho para o nível objetivo da ciência. Daí o autor enunciar, numa entrevista de 1968, "Estruturalismo em lingüística", a necessidade de elaboração paulatina de todo um corpo de definições nesse "imenso domínio".

É preciso ressaltar que os novos objetos, o discurso e a enunciação, com o necessário desdobramento de temas, como o "novo" tema da referência, nunca competiram com o objeto da Lingüística colocado por Saussure: a língua enquanto sistema. O discurso e a enunciação, na perspectiva funcionalista do trabalho de Benveniste, também pertencem à língua. Essa é desdobrada, agora, em forma e funcionamento. Enquanto forma, a língua constitui uma estrutura, mas, enquanto funcionamento, a língua se transforma em discurso e somente o discurso tem referência. 


\section{A QUESTÃO EPISTEMOLÓGICA}

Saussure, procurando encontrar o lugar da língua entre os fatos humanos e elevar a Lingüística à categoria de ciência, havia usado do artifício de filiar a Lingüística à ciência geral dos signos, a Semiologia, sendo essa relegada todavia a um desenvolvimento futuro, cuja missão seria a de definir o signo. Segundo Saussure, a língua, conjunto de signos, acha sua unidade e seu princípio de funcionamento no seu caráter semiológico e é esse caráter que faz com que a Lingüística se integre num conjunto de sistemas do mesmo tipo.

Apesar de ter enunciado que a língua é o mais difundido sistema de expressão e o mais característico de todos, podendo "erigir-se em padrão de toda a Semiologia", porque os signos inteiramente arbitrários, como os signos lingüísticos, são os que realizam melhor do que os outros o procedimento semiológico, as teses de Saussure não avançaram muito no tratamento das relações da Lingüística com a Semiologia. A esse respeito, a única questão tratada no Cours, na verdade a questão que sustenta toda a relação, é o princípio da arbitrariedade do signo, colocado no centro da Lingüística.

Benveniste, procurando preencher esse vazio, ou seja, determinar as relações entre os sistemas semiológicos e o sistema lingüístico, o que equivale a determinar o estatuto da língua em meio aos sistemas de signos, elabora a tese da relação semiótica fundamentalmente dissimétrica entre sistema interpretante (sistema lingüístico) e sistema interpretado (outros sistemas). Segundo essa tese (exposta sobretudo em Semiologia da lingua), os signos da sociedade formam "sistemas interpretados" pelo "sistema interpretante", que a língua é, ou seja, os signos da sociedade sempre supõem a língua, podendo ser integralmente interpretados por ela, mas jamais o inverso. Dito de outro modo: toda semiologia de um sistema não lingüístico deve pedir emprestada a interpretação da língua, e não pode existir senão pela e na semiologia da língua. A língua produz e interpreta todos esses outros sistemas. O que 
equivale a dizer que, considerada a relação de interpretância, que é semiótica, e não a relação de encaixe, que é sociológica, é a Lingüística que contém a Semiologia, é a língua que torna a sociedade possível.

Mas de onde vem essa soberania da língua a ponto de ela poder ser considerada um sistema auto-sustentável e interpretante de todos os outros sistemas semiológicos?

A resposta é que a língua nos fornece, segundo Benveniste, o único modelo de um sistema que seja semiótico simultaneamente na sua estrutura formal e no seu funcionamento, ou melhor, que seja semiótico (estrutura formal) e semântico (funcionamento). Enquanto semântica, a língua se manifesta pela enunciação, que contém referência a uma situação dada. Falar é sempre falar-de. Enquanto semiótica, a língua consiste formalmente de unidades distintas, sendo cada uma delas um signo. Em resumo, porque ela é investida de dupla significância, combinando o modo semiótico de significar com o modo semântico. Os outros sistemas ou são somente semióticos, como os gestos de cortesia, ou são somente semânticos, como as expressões artísticas.

\subsection{O modo semiótico e o modo semântico}

Resumindo-se as colocações de Benveniste, pode-se dizer que o modo semiótico é aquele definido por Saussure, sendo próprio do signo lingüístico considerado no código, fora da mensagem, ou fora do funcionamento da língua. É o modo semiótico que constitui o signo como unidade do sistema: todo signo se conserva enquanto unidade, união de um significante e um significado, ao mesmo tempo que é delimitado pelos significantes semelhantes e significados vizinhos. Existe para ser reconhecido. Segundo Benveniste, o domínio semiótico já tem um aparelho conceptual considerável, que é a teoria de Saussure.

O modo semântico é grande novidade trazida por Benveniste, o qual reconhece a necessidade de um aparelho novo de conceitos 
e definições para dar conta desse dado novo. Sobre ele Benveniste diz que pertence à língua enquanto produtora de mensagem ou a língua em funcionamento, sendo engendrado pelo discurso. Nenhuma mensagem se reduz a uma soma ou sucessão de unidades que devem ser identificadas separadamente. O modo semântico consiste não na significância do signo, mas da enunciação e existe para ser compreendido.

Com o modo semântico, abre-se todo um campo novo para a Lingüística, que se vê agora com uma nova tarefa: a de constituir novos objetos, a de desenvolver novos conceitos, novos temas. O semântico traz de volta, e esta é a grande novidade, a questão da referência. Enquanto semântica, a língua toma necessariamente a seu cargo o conjunto de referentes. O semântico é o "sentido" resultante do encadeamento, da apropriação pela circunstância e da adaptação dos signos entre si, manifestando-se na enunciação, que, conforme já se afirmou, contém referência a uma determinada situação. Enquanto semiótica, a língua é independente de toda referência, formada de signos sem história e sem contexto, cujo sentido é fechado sobre si mesmo e contido de algum modo em si mesmo.

O semântico de Benveniste inclui o pragmático. Considerada como funcionamento ou realização, a língua supõe necessariamente um locutor, um interlocutor e a situação desse locutor no mundo.

A distinção do semiótico e do semântico, instituída por Benveniste, é radical, resultando, na verdade, em duas lingüísticas, com a necessidade proclamada pelo autor da elaboração de métodos e conjuntos conceptuais distintos, estreitamente apropriados a seu objeto. É essa distinção que permite retomar a questão essencial do signo, que é a de significar, a de dizer alguma coisa, de se retomar a ação da linguagem sobre a realidade e de se sair do universo fechado dos signos, ultrapassando-se em muito aquela lingüística que se instaurou precisamente proclamando esse fechamento. A noção de semântica coloca a língua em emprego e ação, na sua função mediadora entre o homem e o homem, entre o homem e o mundo, permitindo a integração da sociedade e a adequação ao mundo. 
Essa radicalidade na distinção entre o semiótico e o semântico, a exigir tratamento metodológico diferenciado, não implica em que Benveniste não tenha considerado a relação entre os dois sistemas. Pelo contrário, na relação é que viu a possibilidade de a língua ser o que ela é. Resolveu a questão através da metáfora das "camadas": o sistema semiótico é a base, onde se organizam os signos, tendo cada um deles uma denotação conceptual; o sistema semântico nutre-se do semiótico. O discurso constrói sobre o fundamento semiótico uma semântica própria, ou seja, a significação do discurso é intencionada, produzida pela sintagmatização das palavras, em que cada palavra não retém senão uma pequena parte do valor que tem enquanto signo pertencente ao sistema semiótico.

\section{O NOVO PLANO DE OBJETOS}

A redução da linguagem à língua por Saussure foi o que permitiu colocar a língua como princípio de unidade, encontrar o lugar da língua entre os fatos humanos. Ambos os princípios, de unidade e de classificação, foram necessários para elevar a Lingüística à categoria de ciência. Não se poderia conceber uma ciência indecisa quanto ao seu domínio ou incerta quanto ao seu objeto.

No deslocamento provocado pelo funcionalismo em lingüística, da segunda metade do século, do qual Benveniste parece ser o mais notável representante, a linguagem continua reduzida à língua, mas a língua se desdobra em forma (estrutura) e funcionamento, e enquanto funcionamento alarga seu domínio de objetos, englobando o discurso e a enunciação. A língua enquanto forma atinge todavia um rigor formal que supera em muito o rigor do próprio Saussure. Esse fato é em grande parte decorrente, conforme se verá abaixo, de uma nova concepção de signo lingüístico.

\subsection{Uma nova concepção de signo}

A tarefa a que se propõe Benveniste, a de ultrapassar a noção saussuriana de signo, enunciada em Semiologia da língua ${ }^{1}$ não se 
restringe à tarefa de simplesmente acrescentar um nível de significância na língua. Mais do que isso, existe uma discordância fundamental entre Benveniste e Saussure, mesmo em se considerando apenas o "nível semiótico" de significância.

Em Natureza do signo lingüistico, texto de 1939, Benveniste já havia proposto algumas mudanças consideráveis quanto à "natureza" do signo lingüístico. Sua tarefa neste artigo é, "sem tirar o mérito de Saussure", especificar melhor a relação do arbitrário do signo, ou seja, "restaurar a verdadeira natureza do signo no condicionamento interno do sistema". Sem a pretensão de alterar no fundamental a tese de Saussure, mas de reforçar, além de Saussure, o rigor do pensamento saussuriano, Benveniste acaba por subverter aquilo que pode ser considerado o núcleo da lingüística, que é a questão do arbitrário do signo.

A relação entre o significante e o significado não é arbitrária, propõe Benveniste, mas necessária. Argumenta que, se a língua é forma, como afirmou Saussure, e de fato parece ser, parece haver uma contradição entre a maneira como Saussure define o signo lingüístico e a natureza fundamental que lhe atribui, pois Saussure pensa sempre, quando fala no arbitrário do signo, na representação do objeto real, embora fale da relação entre o significado (idéia) e o significante. Pensa, na verdade, continua Benveniste, na relação entre o signo e a coisa significada, embora afirme estar falando da relação entre o conceito e a imagem acústica. O que é arbitrário (propõe Benveniste para consertar o engano de Saussure) não é a relação entre o significante e o significado, mas a relação entre o signo e o objeto. Todavia a relação entre o signo e o objeto não diz respeito à forma lingüística, à língua enquanto estrutura, mas tão somente à língua enquanto funcionamento, que não é objeto da lingüística de Saussure. O arbitrário, sustenta Benveniste, só existe em relação com o fenômeno ou o objeto material e não intervém na consideração da estrutura: a relação entre o significante e o significado é uma relação necessária, uma consubstancialidade que garante a unidade estrutural do sistema lingüístico. 
Trata-se, sem dúvida, de uma depuração teórica, de se imprimir um rigor muito maior à noção de forma e estrutura, rigor impossível com o arbitrário do signo. O caráter relativo do valor dos signos, a grande tese de Saussure, somente pode ser garantido então, na argumentação de Benveniste, por uma relação necessária entre o significante e o significado. A língua não se compõe de um conglomerado fortuito de noções erráticas e de sons emitidos ao acaso porque há uma necessidade imanente à sua estrutura: "o caráter absoluto do signo lingüístico assim entendido comanda, por sua vez, a necessidade dialética dos valores em constante oposição e forma o princípio estrutural da língua”. ${ }^{2}$

A nova proposta de Benveniste desloca a mutabilidade e imutabilidade do signo (garantidas, segundo Saussure, pelo arbitrário do signo) da relação entre o significante e o significado para a relação entre o signo e o objeto, ou seja, desloca-a da estrutura para o funcionamento da língua: não é entre o significante e o significado que a relação ao mesmo tempo se modifica e permanece imutável, mas entre o signo e o objeto. A mutabilidade e a imutabilidade do signo estão relacionadas com "a motivação objetiva da designação, submetida, como tal, à ação de diversos fatores históricos". ${ }^{3}$

Assim, para Benveniste, é nessa relação entre o signo e o objeto, arbitrária no caso dos signos lingüísticos, que o signo retém do objeto a formação do conceito, que, distinto do objeto, não é senão um exemplar deste. Garante-se, desse modo, o processo de representação da linguagem. Na base das funções conceptuais, abstratas, próprias do ser humano, reside a capacidade representativa de essência simbólica. A transformação simbólica dos elementos da realidade ou da experiência em conceitos é o processo pelo qual se cumpre o poder racionalizante do espírito humano. O pensamento é, para Benveniste, o poder de construir representações das coisas e de operar sobre essas representações.

Se Benveniste admite a relação do signo com a realidade, a ponto de admitir mudança na relação de designação, não o admite todavia na língua considerada enquanto forma. Nessa não se tem 
que olhar para a realidade; a língua se mantém através de relações absolutas, relações necessárias entre os significantes e os significados e entre os valores lingüísticos em constante oposição. A relação com a realidade, como se viu, dá-se apenas na língua enquanto funcionamento.

É nos trabalhos mais recentes, no entanto, que Benveniste aperfeiçoará a questão do signo e aí não mais falará de signo no funcionamento da língua, mas de palavra, opondo signo, unidade do semiótico ou da língua enquanto estrutura, a palavra, unidade do semântico ou da língua enquanto funcionamento e produtora de mensagem.

\subsection{Signo, palavra e frase}

Considerada ou como forma, ou como funcionamento, o caráter primordial da língua é, para Benveniste, a significação, "sua vocação original que transcende e explica todas as funções que ela assegura no meio humano". ‘ A questão de Benveniste, quer no semiótico, quer no semântico, é a significação, aquilo que é "o próprio da linguagem", atividade significante por excelência.

Como nos faz ver na palestra de 1966, A forma e o sentido na linguagem, do semiótico ao semântico há uma mudança radical de perspectiva. A semiótica se caracteriza como uma propriedade da língua; a semântica resulta de uma atividade do locutor que coloca a língua em ação. A língua enquanto semiótica é feita de signos. A língua enquanto semântica é feita de frases. Enquanto o signo é a unidade semiótica por excelência, sendo a significação o seu limite, a palavra é a unidade semântica, unidade mínima da mensagem e unidade necessária da codificação do pensamento. A expressão semântica por excelência é a frase.

O signo e a frase são, então, para Benveniste, dois mundos distintos, exigindo descrições distintas. O signo semiótico existe em si, funda a realidade da língua, não existindo em aplicações particulares; a frase, expressão do semântico, não é senão particular, 
assim como a palavra, unidade da frase, é sempre particular. Com o signo tem-se a realidade intrínseca da língua; com a frase liga-se a língua às coisas, à realidade fora da língua. Enquanto o signo tem por integrante o significado, que lhe é inerente, o sentido da frase implica referência à situação de discurso e à atitude do locutor.

O "sentido" no semiótico opera nos moldes saussurianos (excetuando-se a questão do arbitrário do signo), definindo-se por uma relação de paradigma: o signo entra numa rede de relações e de oposições binárias com os outros signos que o definem, que o delimitam no interior da língua. O critério necessário e suficiente do semiótico é, pois, a identificação de suas unidades no interior da língua, ou seja, no jogo de distinções entre os signos. É através desse jogo que cada signo significa, tendo de próprio apenas o que o distingue dos outros signos. Do signo semiótico exclui-se qualquer relação com as coisas denotadas, porque o semiótico não se ocupa da relação de referência.

O sentido no semântico se define na frase, na idéia que ela exprime; este sentido se realiza formalmente na língua pela escolha, pelo agenciamento das palavras, por sua organização sintática, pela ação que elas exercem sobre as outras. Tudo é dominado pela condição do sintagma, pela ligação entre os elementos do enunciado destinado a transmitir um sentido dado, numa circunstância dada. Uma frase participa sempre do aqui e agora ou de um certo presente de um certo locutor.

A frase tem sentido e tem forma. O sentido ou a mensagem está na totalidade da idéia percebida por uma compreensão global. A forma se obtém pela dissociação analítica do enunciado em palavras. O sentido da frase é diferente do sentido das palavras que a compõem. Enquanto o sentido de uma frase é sua idéia, o sentido de uma palavra é seu emprego (sempre na acepção semântica). No emprego da frase, as palavras têm um sentido particular, o seu sentido consistirá na sua capacidade de ser integrante de uma frase e de preencher uma função proposicional.

A frase ainda tem referência. O sentido da frase é a idéia que ela exprime, a referência da frase é o estado de coisas que a provoca, 
a situação de discurso ou de fato a que ela se reporta e que nós não podemos jamais prever ou fixar.

Resumindo-se as colocações de Benveniste sobre signo, palavra, e frase, pode-se dizer que enquanto o signo tem sempre valor genérico e conceptual, não admitindo significado particular ou circunstancial, o sentido das palavras se determina em relação ao contexto da situação. A palavra, particular, específica, circunstancial, acepção contingente do discurso, é a atualização do signo. A frase não tem espaço no domínio do semiótico, o que equivale a dizer que não existe frase disponível em língua. A frase é invariavelmente de domínio do discurso.

\section{A QUESTÃO DA REFERÊNCIA}

A questão da relação da linguagem com a realidade acha-se presente em todo o trabalho de Benveniste, mas é no artigo de 1970, O aparelho formal da enunciação, ${ }^{5}$ que a referência aparece como parte integrante da enunciação, sendo essa concebida, por sua vez, como um processo de apropriação individual da língua pelo locutor:

Por fim, na enunciação, a língua se acha empregada para a expressão de uma certa relação com o mundo. A condição dessa mesma mobilização e dessa apropriação da língua é, para o locutor, a necessidade de referir pelo discurso e, para o outro, a possibilidade de co-referir identicamente, no consenso pragmático que faz de cada locutor um co-locutor. A referência é parte integrante da enunciação. (Benveniste, 1970:84).

É a primeira vez que a referência é tirada do isolamento do signo e incluída no quadro da enunciação, ou seja, no funcionamento dialógico da língua, que inclui locutor, alocutário, contexto situacional. $^{6}$

A enunciação, esse "colocar a língua em funcionamento" por um ato individual de apropriação, que supõe a conversão da língua em discurso, não é, para Benveniste, a fala de Saussure, não é o texto 
do enunciado, não é o discurso. O discurso é a manifestação da enunciação ou o seu produto. A enunciação não é produto, mas o ato de produzir o enunciado, antes do qual a língua não é senão uma possibilidade.

O valor de referência é conferido pela enunciação, ou seja, a língua deve ser considerada na medida em que, através do sujeito falante, no ato de enunciação, ela se refere ao mundo. E o centro desse ato de referência é o sujeito falante, que enuncia sua posição de locutor através de índices específicos, ou caracteres formais, tais como os índices de pessoa, os índices de ostentação, as formas temporais que se determinam em relação ao $e u$, centro da enunciação, as formas lexicais e sintáticas da interrogação, da intimação, da asserção, as modalidades formais pertencentes aos verbos, à fraseologia. O conjunto desses elementos, índices, na verdade, que nascem na e pela enunciação, Benveniste chama de "aparelho formal da enunciação".

Essa concepção de referência evidencia a evolução sofrida pelo pensamento do autor, mostrando-se perfeitamente coerente com a concepção dos dois modos de significância, o semiótico e o semântico, expresso em Semiologia da língua.

\subsection{A evolução no conceito de referência}

Nos trabalhos mais antigos, anteriores à década de 60, Benveniste concebia dois planos ou dois lugares de referência, correspondentes a duas realidades diferentes: a realidade subjetiva do discurso e a realidade objetiva do mundo fenomenal. Para sustentar essa dualidade, aparecia um elenco de oposições outras, tais como pessoa/não pessoa, discurso/narrativa histórica, as quais, no entanto, parecem cair por terra nos trabalhos mais recentes, quando a referência é considerada exclusividade do modo semântico de significar.

A oposição pessoa (primeira e segunda pessoas)/não pessoa (terceira pessoa) é desenvolvida no texto de 1956, A natureza dos 
pronomes. Através dessa distinção, Benveniste defendia uma estabilidade de significação para os signos de terceira pessoa, não dêiticos, mesmo quando atualizados no funcionamento da língua. Nesse texto Benveniste contrasta tanto a categoria não pessoa ("referencial em relação à realidade", empregada no "uso cognitivo da língua") como a categoria dos signos plenos (disponíveis na língua enquanto sistema), com os índices (dêiticos ou indicadores).

A não pessoa ou terceira pessoa é concebida com um estatuto pleno de referência, ou seja, podendo referir-se à realidade objetiva ou ao mundo fenomenal, independentemente das suas condições na enunciação. Os signos plenos são concebidos como existindo virtualmente na estrutura da língua, remetendo a uma situação objetiva no tempo e no espaço, significando sempre o mesmo, independentemente de quem, do quando, do onde, por oposição aos dêiticos, que só podem existir na medida em que são atualizados na instância do discurso. Para os signos plenos, portadores de uma "noção constante", sempre há um objeto definível ao qual podem remeter identicamente, o que equivale a dizer que podem sempre ocorrer com a mesma referência. Para os dêiticos ou indicadores, há que se conceber sempre uma referência própria, dependente de cada instância de discurso.

Desse modo, os signos da língua (exceto os pronomes e o aparelho formal da enunciação), signos plenos, distribuem-se indiferentemente nos discursos e nas narrativas históricas. "Cada instância de um nome (língua em funcionamento) refere-se a uma noção constante e "objetiva", apta a permanecer virtual ou a atualizar-se num objeto singular e que permanece sempre idêntica na atualização que desperta".

A oposição discurso/enunciação bistórica é tratada no texto de 1959, As relações de tempo no verbo francês. Somente a enunciação em primeira pessoa é considerada discurso. A narrativa impessoal ou histórica, em que não intervém o narrador, aquele que diz eu, não é considerada discurso. No domínio dessa, a terceira pessoa não tem o mesmo valor que no discurso. A terceira pessoa 
não tem uma primeira para se opor, constituindo-se em uma ausência de pessoa.

A concepção de referência que Benveniste fazia dos "signos plenos", que cumprem uma função representacional, simbólica, constatativa (por oposição à "primeira e segunda pessoas", que cumprem uma função enunciatória ou discursiva) provém das teorias clássicas. Nessas, a referência repousa na capacidade lingüística de representação do signo lingüístico. Atribuir uma referência a um nome, independentemente de sua atualização no discurso, é dotálo de uma representação objetiva, universal.

Essa concepção de referência, que não reserva espaço algum ao subjetivo e aos índices (dêiticos), foi a grande tese de Frege, o filósofo que, na passagem do século passado para o atual, traçou o quadro da Semântica Lógica, no interior do qual ainda se move grande parte da filosofia analítica anglo-saxônica. Não se pode negar nos trabalhos mais antigos de Benveniste uma certa influência de Frege, autor que Benveniste parecia conhecer muito bem.

Em O aparelho formal da enunciação, Benveniste parece não mais admitir dois planos de referência. Os conceitos de discurso e enunciação se alargam. O autor não mais fala em dois tipos de enunciação, o que se pode entender como o cancelamento da oposição entre enunciação em primeira pessoa (ou discurso) e enunciação em terceira pessoa (ou narrativa histórica). Toda enunciação, explícita ou implicitamente (com ou sem a ostentação de índices de primeira pessoa) é uma alocução. Também não mais existem "indivíduos lingüísticos" que não sejam afetados pelo ato de enunciação.

No texto de 1970, já não existe, portanto, referência fora da enunciação, o que é reafirmado em outros trabalhos, nos quais Benveniste proclama que não existe referência no semiótico, mas apenas no semântico. A enunciação é, agora, um mecanismo total e constante que, de uma maneira ou de outra, afeta a língua inteira. A referência passa a ser condição da enunciação. A condição de o locutor se apropriar da língua, mobilizá-la por sua conta, é a 
necessidade de referir pelo discurso. Para o alocutário, a condição é a possibilidade de co-referir identicamente. O mecanismo de referência necessita de condições especiais, tais como: a língua enquanto possibilidade, o locutor que se apropria da língua para efetuá-la numa instância de discurso, o alocutário (o tu da interlocução), o ato de enunciação, o discurso (o produto da enunciação). Cada instância de discurso deve ser considerada num centro de referência interno.

O referente, desnecessário antes, na estrutura da língua, fazse agora necessário no seu funcionamento pelo discurso. Trata-se do objeto particular a que a palavra corresponde no caso concreto da circunstância ou do uso.

Esse deslocamento da referência, da estrutura da língua para o seu funcionamento ou uso, abriu um debate, pioneiro no seio da lingüística. Cumpre ressaltar que um debate análogo já vinha há muito sendo feito no interior da filosofia da linguagem, sobretudo pelos filósofos da moderna tradição analítica (os quais Benveniste sem dúvida conhecia), tendo começado com Wittgenstein e sendo alimentado, na época de Benveniste, por Strawson, Donnellan, Austin, para não citarmos outros nomes. Esses filósofos contestavam o princípio fregeano segundo o qual o sentido determina a referência, procurando deslocar a referência do sistema lógico-formal da língua para a linguagem em uso, em circunstâncias adequadas.

\subsection{Referência, representação e subjetividade}

O signo é, para Benveniste, representação. E isso ele o diz reiteradas vezes, tanto nos textos mais antigos, quando defendia a existência de signos plenos (com uma estabilidade referencial garantida independentemente das instâncias de discurso) em oposição aos indicadores (que se referem à realidade de discurso que os contém, realidade sempre única) como nos textos mais recentes, em que já defende ser a referência parte integrante da enunciação. O signo é unidade da língua e tem a função de 
representar, de estar no lugar de outra coisa, o de tomar o lugar de outra coisa, evocando-a a título de substituto. ${ }^{8} \mathrm{O}$ signo deve ser compreendido como representante do real, ou seja, com a função de estabelecer uma significação entre algo e algo diferente. ${ }^{9}$ Ora, esse algo diferente é o referente, o terceiro termo, banido da concepção saussuriana de signo.

Benveniste sempre afirmou que o caráter comum a todos os sistemas e o critério de sua ligação à Semiologia é a sua propriedade de significar ou significância e sua composição em unidades de significância, os signos. Para alguma coisa ser dotada de significação, tem que designar. É graças ao signo, entendido como representação, que a linguagem desempenha a faculdade de simbolizar.

A função simbólica ou mediadora da linguagem é tratada mais especificamente num artigo de 1963, Vista d'olhos sobre o desenvolvimento da lingüística, em que o autor admite que a linguagem, considerada enquanto função (não forma ou estrutura) reproduz o mundo, devendo-se entender, todavia, nessa "representação" ou "reprodução" uma submissão do mundo pela linguagem. Sendo logos (discurso e razão juntas), a linguagem submete o mundo à sua própria organização, interpretando os acontecimentos, as situações, classificando e nomeando os objetos, o que equivale a dizer, constituindo-os como referentes da linguagem.

A língua enquanto funcionamento é inseparável de uma função social, cultural, e pode ser considerada no seu aspecto de representação: "a linguagem reproduz a realidade. Isso deve entender-se da maneira mais literal: a realidade é produzida novamente por intermédio da linguagem". ${ }^{10}$

$\mathrm{Na}$ perspectiva funcionalista de Benveniste, que considera o diálogo como a situação inerente ao exercício da linguagem, a função de representação da linguagem está ligada à função de comunicação: o locutor reproduz o acontecimento através de sua fala, que representa, assim, a realidade; o ouvinte apreende a fala do locutor e através da compreensão da fala do outro apreende a reprodução do acontecimento e recria a realidade. 


\section{QUESTÕES PENDENTES}

Apesar do grande avanço dado por Benveniste com a introdução do tema da referência no seio da lingüística moderna, o que abre grandes perspectivas de pesquisa e estudos da linguagem combinados com um interesse por problemas sociais, não é muito fácil sustentar o caráter representacional do signo na obra de Benveniste, ou defender a tese da constituição dos referentes do mundo como referentes da linguagem, se se considerar que, para Benveniste, tudo no semântico, onde se dá a relação da linguagem com a realidade (a palavra, a frase, o discurso, a referência, a enunciação), é concebido com valores subjetivos e individuais.

Se, de um lado, pertencer à enunciação parece ser o dispositivo que faltava para colocar a relação entre a linguagem e a realidade em processo de contínua reconstrução, de outro lado, parece complicado tentar garantir esse dinamismo entre a linguagem e a realidade através de uma concepção de enunciação presa à subjetividade e à pragmática elementar do aqui e agora do ato de discurso.

A referência, tão circunstancial quanto o discurso, a frase e a enunciação, acaba sendo apenas um acontecimento, pode-se dizer, um acontecimento que desaparece. Não existe senão no instante em que é a frase é proferida e se apaga neste mesmo instante. Presa à fugacidade da enunciação, é concebida independentemente do jogo de influências sociais condicionantes, ou seja, de uma maneira não muito comprometida com as determinações histórico-sociais a que todo discurso deve estar sujeito.

Ignoram-se ainda os lugares sociais de onde falam os interlocutores. Ora, esse processo dinâmico de (re)construção, em que se colocam a linguagem e a realidade, não pode ser considerado ideologicamente neutro, porque a ação humana é marcada por relações hegemônicas, relações contudo passíveis de serem transformadas.

Como assegurar, dessa forma, com valores subjetivos e individuais, o simbólico da língua ou a transformação simbólica dos 
elementos da realidade e da experiência? Parece mais certo que para que o signo possa reter do objeto a formação do conceito, através da relação da linguagem com a realidade, faz-se necessário operar com valores de outra ordem.

Mesmo tendo Benveniste afirmado reiteradas vezes que a língua é determinada pela cultura, ${ }^{11}$ pelo social, que nenhuma língua é separável de uma função cultural, e que, por outro lado, é a linguagem que nos dá o mundo, pois é somente através da fala que a criança aprende que se adquire o mundo no qual se vive na realidade, seu nível de reflexão e elaboração teórica jamais permitiu que se avançasse muito com referência a essa relação dinâmica entre o lingüístico e o social.

Não fica igualmente resolvida a questão da mutabilidade/ imutabilidade do signo. Já se disse aqui que Benveniste deslocou a mutabilidade e a imutabilidade do signo da relação entre o significante e o significado para a relação entre a palavra e o objeto, a saber, do semiótico para o semântico. Viu-se, entretanto, que a relação entre a palavra e a realidade, da forma como Benveniste a concebe, opera somente no funcionamento da língua através de atos de enunciação considerados subjetivos e únicos. A questão que então aqui se coloca é: como colocar a língua em evolução, se a língua funciona somente no individual e no subjetivo? Como garantir o processo histórico de evolução por atos cada vez únicos de enunciação?

\section{CONSIDERAÇÕES FINAIS}

A prática discursiva das ciências e disciplinas do século XX rejeita objetos subjetivos e individuais. A Lingüística somente se constituiu como ciência graças à marginalização da fala e de todos os fatores subjetivos e individuais da linguagem. Todavia, a língua, concebida como sistema ou estrutura, em que os valores são relativos e diferenciais, acabou por bloquear todo o processo de significação e de mudança lingüística. Faltava à Lingüística um dispositivo que 
colocasse a língua em processo, libertando-a do fechamento e da imobilidade da estrutura. Esse dispositivo não poderia contudo ser subjetivo. A fala de Sausssure ou algum aparentado seu não teria espaço no discurso das ciências.

Benveniste viu uma saída para promover a abertura da língua para a realidade, através do processo de enunciação. Concebeu, porém, a enunciação dentro da subjetividade e da singularidade de cada ato de discurso, o que acabou fazendo com que sua obra recebesse duras críticas. Não se podia negar, porém, que o "ovo de Colombo" estava colocado, necessitando-se apenas desguarnecê-lo, num desdobramento posterior, do envólucro da subjetividade.

Ainda que se considere hoje, na era de Freud, Lacan, Heidegger e muitos outros críticos da autonomia do sujeito, o trabalho de Benveniste problemático, sobretudo por sua concepção subjetiva de enunciação e discurso, não se pode negar que o essencial do objetivo de Benveniste permanece nas atuais abordagens lingüísticas que priorizam o discurso: colocar a enunciação no coração do dispositivo gramatical. A realidade não existe em si e por si como um objeto dado, objeto de contemplação, esperando para ser conhecido e interpretado, mas a realidade existe e é inteligível somente com relação à ação humana, na qual a linguagem, como prática discursiva, ocupa um lugar fundamental, por ser constituída nessa relação e ao mesmo tempo constitutiva dessa relação.

\section{NOTAS}

${ }^{1}$ Na verdade, já enunciada na palestra de 1966, A forma e o sentido na linguagem (Problemas de lingüistica geral II).

${ }^{2}$ Natureza do signo lingüístico (Problemas de lingüistica geral I, p. 59).

${ }^{3}$ Idem, p. 58.

${ }^{4}$ A forma e o sentido na linguagem (Problemas de lingüistica geral II, p. 222). 
${ }^{5}$ Nesse artigo, o autor pretende definir a enunciação no quadro formal de sua realização, tentando esboçar no interior da língua os caracteres formais da enunciação. Para tanto, defende que a língua tem um aparelho formal da enunciação, "indivíduos lingüísticos" que emanam da enunciação.

${ }^{6}$ Esse processo já havia sido considerado por Bakhtin, na obra Marxismo e filosofia da linguagem, de 1929, mas nos domínios da Filosofia da Linguagem. Todavia, para Bakhtin, a enunciação não é individual, mas eminentemente social.

${ }^{7}$ A natureza dos pronomes (Problemas de lingüistica geral I, p. 278).

${ }^{8}$ Semiologia da língua (Problemas de lingüística geral II, p. 51).

${ }^{9}$ Vista d'olhos sobre o desenvolvimento da lingüística (Problemas de lingüistica geral I, p.19).

${ }^{10}$ Idem, p. 26.

${ }^{11}$ Estruturalismo e lingüística (Problemas de lingüística geral II, p.p. 23 e 24).

\section{REFERÊNCIAS BIBLIOGRÁFICAS}

BAKHTIN, M. Marxismo e filosofia da linguagem. São Paulo: Hucitec, 1988. Trad. bras. com base na tradução francesa de 1977, do original russo de 1929.

BENVENISTE, E. Problemas de lingüistica geral I. Campinas: Pontes, 1988. Trad. bras. de Problèmes de linguistique générale I, 1966.

. Problemas de lingüística geral II. Campinas: Pontes, 1989. Trad. bras. de Problèmes de linguistique générale II, 1974.

FOUCAULT, M. A arqueologia do saber. Rio de Janeiro: Forense-Universitária, 1987. Trad. bras. de L'archéologie du savoir, 1969.

. L'Ordre du discours. Paris: Gallimard, 1971.

SAUSSURE, F. Curso de lingüística geral. São Paulo: Cultrix, 1971. Trad. bras. de Cours de linguistique générale, 1916. 